\title{
Experimental study on the mechanism and development effect of multi-gas assisted steam huff and puff process in the offshore heavy oil reservoirs
}

\author{
Jie Fan ${ }^{1,2}$ - Zuqing He ${ }^{1} \cdot$ Wei Pang ${ }^{1} \cdot$ Daoming Fu ${ }^{1} \cdot$ Hanxiu Peng ${ }^{1} \cdot$ Huanle Liu ${ }^{1}$
}

Received: 3 August 2021 / Accepted: 25 August 2021 / Published online: 7 September 2021

(c) The Author(s) 2021

\begin{abstract}
Multi-gas assisted steam huff and puff process is a relatively new thermal recovery technology for offshore heavy oil reservoirs. Some blocks of Bohai oilfield have implemented multi-gas assisted steam huff and puff process. However, the development mechanism still requires further study. In this paper, high-temperature high-pressure (HTHP) PVT experiments and different huff and puff experiments of sand pack were carried out to reveal the enhanced production mechanism and evaluate the development effect of multi-gas assisted steam huff and puff process. The results indicated that viscosity reduction and thermal expansion still were the main development mechanism of multi-gas assisted steam huff and puff process. Specifically, $\mathrm{CO}_{2}$ easily dissolved in the heavy oil that made it mainly play the role of reducing oil viscosity, $\mathrm{N}_{2}$ was characteristics of small solubility and good expansibility, and it could improve formation pressure, increase steam sweep volume and even reduce the heat loss. Meanwhile, injecting multi-gas and steam could break the balance of heavy oil component that made the content of resin reduce and the content of saturates, aromatics and asphaltene increase so as to further reduce the viscosity of heavy oil. Compared with steam huff and puff process, multi-gas assisted steam huff and puff process increased the recovery by $2-5 \%$. The optimal water-gas ratio and steam injection temperature were $4: 6$ and $300^{\circ} \mathrm{C}$, respectively. The results suggested that multi-gas assisted steam huff and puff process would have wide application prospect for offshore heavy oil reservoirs.
\end{abstract}

Keywords Offshore heavy oil $\cdot$ Multi-gas assisted steam huff and puff $\cdot$ Mechanism $\cdot$ Development effect $\cdot$ Recovery

\section{Introduction}

As one of main methods for producing heavy oil, steam huff and puff process is characterized of simple process and wide applicability for heavy oil reservoirs. However, steam huff and puff process is classified into primary oil recovery mainly depending on natural energy (Liu 2013; Wang et al. 2004; Sun et al. 2017, 2018a, b, 2019; Yoelin 1970; Bao et al. 2016). For the conventional steam huff and puff process, specifically in the later stage of steam huff and puff process, the thermal efficiency of steam is dramatically reduced

Jie Fan

petrol_yongjf6@163.com

1 SINOPEC Research Institute of Petroleum Engineering, Beijing 102206, China

2 College of Petroleum Engineering, China University of Petroleum, Beijing 102249, China that leads to the recovery decrease. Thus, an improvement recovery process is required.

Previous research results show that injecting gas such as $\mathrm{CO}_{2}, \mathrm{~N}_{2}$ or flue gas can increase the steam sweep volume, supplement the formation energy and further reduce the viscosity of heavy oil and residual oil saturation (Gao et al. 2003; Firouz and Torabi 2014; Mohsenzadeh et al. 2016; Wang et al. 2018, Fan et al. 2019). For example, at the same time as steam injection, injecting $\mathrm{CO}_{2}$ can reduce the viscosity of heavy oil and thereby increase the recovery of heavy oil (Li et al. 2017; Liu et al. 2016; Wang et al. 2018; Dong and Huang 2002; Dong et al. 2014; Song and Yang 2017). Specifically, $\mathrm{CO}_{2}$ is easily dissolved into crude oil, which increases the volume of crude oil by $10-30 \%$, and then the viscosity of crude oil will appear a certain degree decline which depends on pressure, temperature and the properties of crude oil. Meanwhile, crude oil extraction by $\mathrm{CO}_{2}$ is a process where the interfacial tension between $\mathrm{CO}_{2}$ and crude oil continuously decreases. 
$\mathrm{N}_{2}$ injection will help maintain formation pressure, prolong the huff and puff cycle, improve the steam sweep volume and increase the displacement efficiency in the immediate vicinity of wellbore (Wu et al. 2018; Liu et al. 2011; Dong et al. 2016). Considering that $\mathrm{N}_{2}$ has lower thermal conductivity, after injecting $\mathrm{N}_{2}$ into reservoir, steam could be bring into the further area of reservoir which increases the heating volume and sweep efficiency of steam. What's more, as the pressure decreases in the course of development, $\mathrm{CO}_{2}$ and $\mathrm{N}_{2}$ will extract from crude oil and generate dissolved gas drive in the later stage. In view of these, injection $\mathrm{CO}_{2}$ and $\mathrm{N}_{2}$ would have positive effect for production heavy oil in the course of steam injection (Hong and Ault 1984; Butler et al. 2000; Fan et al. 2016; Jin et al. 2017; Yan et al. 2020).

Heavy oil resource is abundant in the Bohai oilfield of China. Heavy oil with the viscosity of less than $350 \mathrm{mPa} \cdot \mathrm{s}$ can be effectively developed by cold recovery technology, such as water flooding, chemical flooding and well pattern thickening. However, for heavy oil with the viscosity of greater than $350 \mathrm{mPa} \cdot \mathrm{s}$, just limited reserves could be developed with the cold recovery technology. At this time, steam huff and puff process will become an effective way of development. But the reservoir type of Bohai oilfield is complex and diverse, viscosity of heavy oil in some blocks can exceed $10000 \mathrm{mPa} \cdot \mathrm{s}$, the development effect of simple steam huff and puff process is not ideal for this kind of heavy oil, a more reasonable development method is needed. Injecting gas such as $\mathrm{CO}_{2}, \mathrm{~N}_{2}$ and flue gas during steam huff and puff process has been generally applied to develop heavy oil reservoirs in onshore oilfield and achieved success. Therefore, multi-gas assisted steam huff and puff process should improve the production effect of offshore heavy oil reservoirs like Bohai oilfield (Liu et al. 2011; Gu et al. 2007).

In this paper, firstly, the influence of $\mathrm{CO}_{2}$ and $\mathrm{N}_{2}$ injection on the solubility, density and viscosity of heavy oil was studied by HTHP PVT experiments based on the offshore heavy oil of Bohai oilfield. Then sand pack experiments were carried out to compare the development effect of different huff and puff process and the change of crude oil component so as to further reveal the development mechanism of multi-gas assisted steam huff and puff process. Finally, 10 groups of sand pack experiments were conducted to optimize the key parameters of water-gas ratio and steam injection temperature. All the study results could provide theoretical and application support for the multi-gas assisted steam huff and puff process in offshore heavy oil reservoirs like Bohai oilfield.
Table 1 The properties of degassed heavy oil

\begin{tabular}{|c|c|c|}
\hline & $\begin{array}{l}\text { Viscosity of heavy } \\
\text { oil at } 50{ }^{\circ} \mathrm{C} / \mathrm{mPa} \cdot \mathrm{s}\end{array}$ & $12,574.2$ \\
\hline & $\begin{array}{l}\text { Density of super- } \\
\text { heavy oil at } \\
20^{\circ} \mathrm{C} / \mathrm{g} \cdot \mathrm{cm}^{-3}\end{array}$ & 0.943 \\
\hline & SARA/ $\%$ & \\
\hline & Asphaltene & 21.94 \\
\hline & Resin & 23.53 \\
\hline & Aromatics & 22.36 \\
\hline & Saturates & 32.17 \\
\hline
\end{tabular}

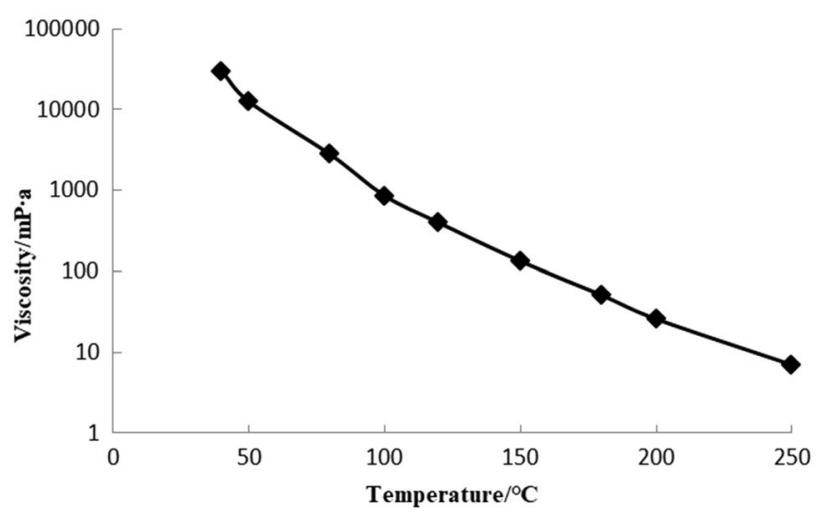

Fig. 1 Relation between viscosity of heavy oil and temperature

\section{Experiment}

\section{HTHP PVT experiment}

\section{Experimental sample}

The crude oil was collected from the Bohai oilfield which is a heavy oil reservoir with the formation depth of $1510.2 \mathrm{~m}$ and original pressure of $15.06 \mathrm{Mpa}$. The oil sample was cleaned by using a centrifuge to remove any sand particles and brine. Table 1 shows the physical properties of oil sample. Density and viscosity of the oil sample were, respectively, measured by a densitometer (DMA 4200 M, Anton Paar, Austria) and a rheometer (MCR302, Anton Paar, Austria). The asphaltene content of the crude oil was measured by using the standard ASTM D2007-03 method and filter papers with a pore size of $2.5 \mu \mathrm{m}$. Figure 1 displays the oil viscosity under different temperature. 


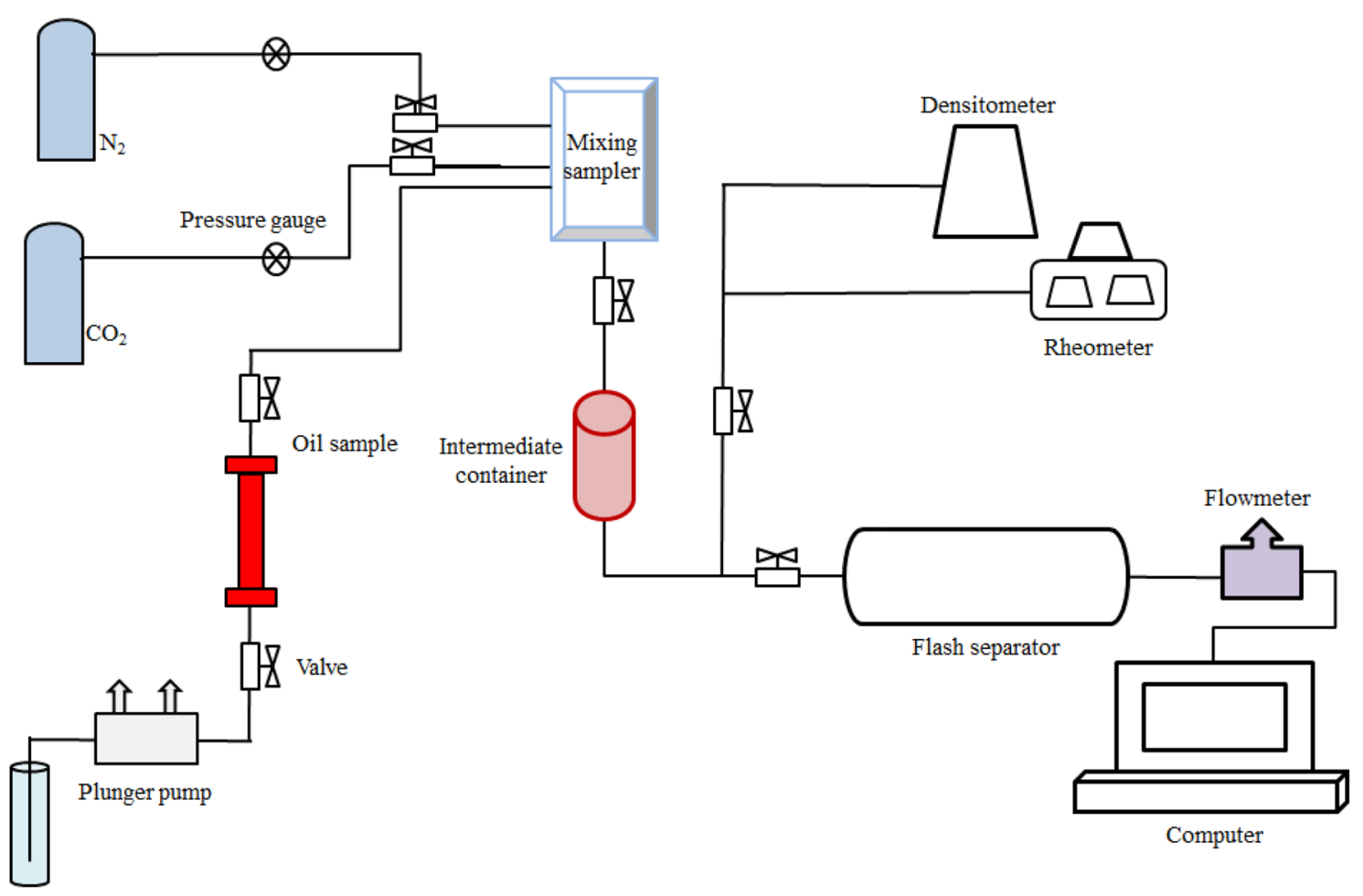

Fig. 2 Schematic apparatus of HTHP PVT experiment

\section{Experimental apparatus}

Figure 2 shows the experimental apparatus for measuring the solubility, density and viscosity of heavy oil saturated with $\mathrm{CO}_{2}$ or $\mathrm{N}_{2}$. The experimental apparatus mainly included sample mixer, intermediate container, flash separator, densitometer, rheometer and computer.

\section{Experimental procedure}

Figure 3 displays the experimental process. Firstly, the degassed heavy oil and enough $\mathrm{CO}_{2}$ or $\mathrm{N}_{2}$ were injected into the sample mixer and mixed well under the designated temperature $\left(80{ }^{\circ} \mathrm{C}, 100{ }^{\circ} \mathrm{C}, 150{ }^{\circ} \mathrm{C}, 200{ }^{\circ} \mathrm{C}\right)$ and pressure (3 $\mathrm{MPa}, 5 \mathrm{MPa}, 8 \mathrm{MPa}, 10 \mathrm{MPa}, 12 \mathrm{MPa}$ ) and, secondly, opened the valve between the sample mixer and intermediate container and injected the mixed heavy oil into the $50-\mathrm{mL}$ intermediate container until it was full. Thirdly, the heavy oil saturated with $\mathrm{CO}_{2}$ or $\mathrm{N}_{2}$ was moved into the flash evaporator, densitometer or rheometer from the intermediate container to test the parameter under the designated temperature and pressure. Finally, the solubility was calculated by the computer connected to the gas flow meter. The density and viscosity were measured by the densitometer and rheometer (Jha 1986; Srivastava et al. 1997; Kavousi et al. 2014; Telmadarreir et al. 2016; Hatzikiriakos 2014).

\section{Huff and puff experiment}

\section{Experimental sample}

The heavy oil sample was from Bohai oilfield, and the initial oil saturation of the reservoir was $72 \%$. The physical properties of heavy oil sample are shown in Table 1 and Fig. 1. Purity of $\mathrm{CO}_{2}$ and $\mathrm{N}_{2}$ (Tianyuan, Co., Ltd., China) was $99.99 \mathrm{~mol} \%$. The property of the formation water is

Fig. 3 Schematic process of HTHP PVT experiment




Table 2 The properties of formation water

\begin{tabular}{llllllll}
\hline $\mathrm{Na}^{+}+\mathrm{K}^{+} / \mathrm{mg} \cdot 1^{-1}$ & $\mathrm{Mg}^{++} / \mathrm{mg} \cdot 1^{-1}$ & $\mathrm{Ca}^{++} / \mathrm{mg} \cdot 1^{-1}$ & $\mathrm{Cl}^{-} / \mathrm{mg} \cdot 1^{-1}$ & $\mathrm{SO}_{4}{ }^{2-} / \mathrm{mg} \cdot 1^{-1}$ & $\mathrm{HCO}_{3}{ }^{-} / \mathrm{mg} \cdot 1^{-1}$ & $\mathrm{CO}_{3}{ }^{2-} / \mathrm{mg} \cdot 1^{-1}$ & $\begin{array}{l}\text { Total mineralization/ } \\
\mathrm{mg} \cdot 1^{-1}\end{array}$ \\
\hline 958.3 & 3.6 & 6.0 & 443.3 & 9.6 & 857.1 & 90.0 & 2388.0 \\
\hline
\end{tabular}

shown in Table 2, with a density of $1.01 \mathrm{~g} / \mathrm{cm}^{3}$ under standard condition.

\section{Experimental apparatus}

As shown in Fig. 4, the experimental apparatus mainly consisted of sand pack, steam generator, plunger pump, flowmeter, calorstat and beaker, etc. The maximum steam output temperature and pressure of steam generator were $400{ }^{\circ} \mathrm{C}$ and $35 \mathrm{MPa}$, respectively. Operating range of calorstat was $0-350{ }^{\circ} \mathrm{C}$. Working range of pressure meter was 0-30 MPa. Working range of plunger pump was 0-50 mL/ min, and maximum pressure was $25 \mathrm{MPa}$. The size of sand pack model was $48 \mathrm{~mm} \times 340 \mathrm{~mm}$, its maximum bearing pressure was $35 \mathrm{MPa}$.

\section{Experimental procedure}

The specific experimental procedures are as follows:

(1) Filled sand: erected the model, filled simulated sand from the upper port and blocked the port after the sand reached the filling port, shook the model by small amplitude in the middle axis and static $1 \mathrm{~h}$, opened the port and continued to fill the sand. Repeated the opera- tion several times until the sand was no longer reduced from the filling port.

(2) Saturated formation water: constant temperature $70{ }^{\circ} \mathrm{C}$, injected formation water into the sand pack at $25 \mathrm{~mL} /$ min until the producing port met the water, continuously injected formation water $1 \mathrm{~h}$. Stopped injecting water and kept the temperature. The sand pack had a permeability of water phase between 3574 and 3862 md, and porosity between 33.7 and $37.6 \%$.

(3) Saturated oil: Injected oil into the sand pack at $20 \mathrm{~mL} /$ min, drained off water until the output liquid of model was not hydrated and continuously injected oil $1 \mathrm{~h}$. Stopped injecting oil and kept the constant temperature. The oil saturation of sand pack was between 71 and $73 \%$.

(4) Different huff and puff experiment: injected hot water/ steam into the sand pack at $20 \mathrm{~mL} / \mathrm{min}$. During the multi-gas assisted steam huff and puff experiment, the water-gas ratio was 1:2.
Fig. 4 Schematic apparatus of huff and puff experiment

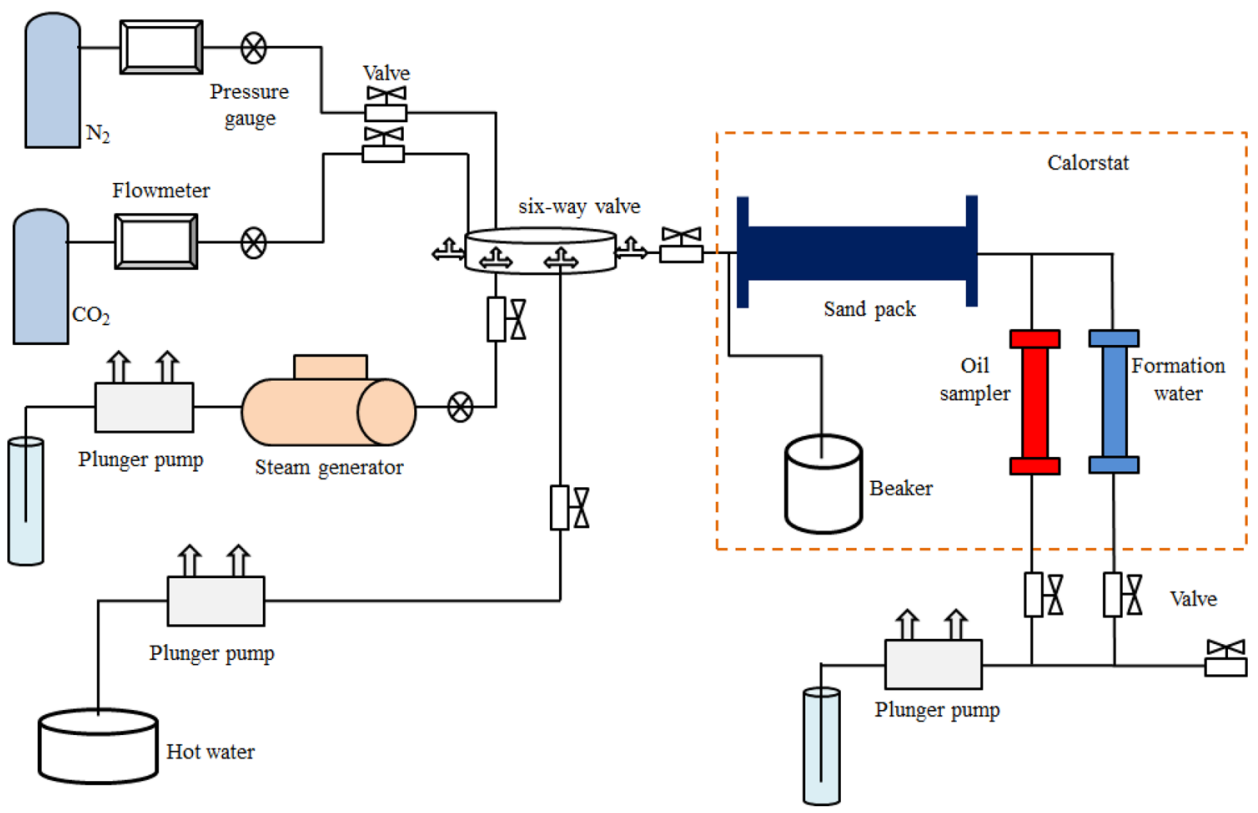




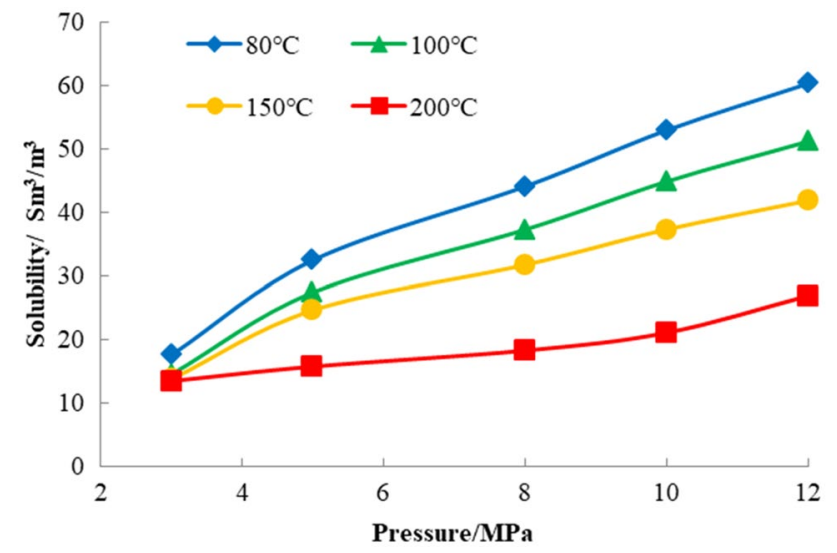

Fig. 5 Relationship between $\mathrm{CO}_{2}$ solubility and pressure at different temperature in heavy oil



Fig. 6 Relationship between $\mathrm{N}_{2}$ solubility and pressure at different temperature in heavy oil

\section{The results and discussion of experiment}

\section{The results and discussion of HTHP PVT experiment}

\section{The solubility of $\mathrm{CO}_{2}$ and $\mathrm{N}_{2}$ in the heavy oil}

Figures 5 and 6 show the relationship between solubility of $\mathrm{CO}_{2}$ and $\mathrm{N}_{2}$ in the heavy oil and pressure at different temperature. It can be seen that the solubility of $\mathrm{CO}_{2}$ and $\mathrm{N}_{2}$ in degassed heavy oil increased as the pressure increased. With the increase in temperature, the solubility of $\mathrm{CO}_{2}$ decreased and the solubility of $\mathrm{N}_{2}$ increased. When the pressure was fixed at $12 \mathrm{MPa}$, the solubility of $\mathrm{CO}_{2}$ in heavy oil decreased from 60.2 to $26.8 \mathrm{Sm}^{3} / \mathrm{m}^{3}$ as the temperature increased from 80 to $200{ }^{\circ} \mathrm{C}$, but the solubility of $\mathrm{N} 2$ in heavy oil increased from 2.9 to $8.1 \mathrm{Sm}^{3} / \mathrm{m}^{3}$ in the process. Under the same condition, the solubility of $\mathrm{CO}_{2}$ was obvious higher than that of $\mathrm{N}_{2}$. When the pressure



Fig. 7 Relationship between density of heavy oil saturated with $\mathrm{CO}_{2}$ and pressure at different temperature

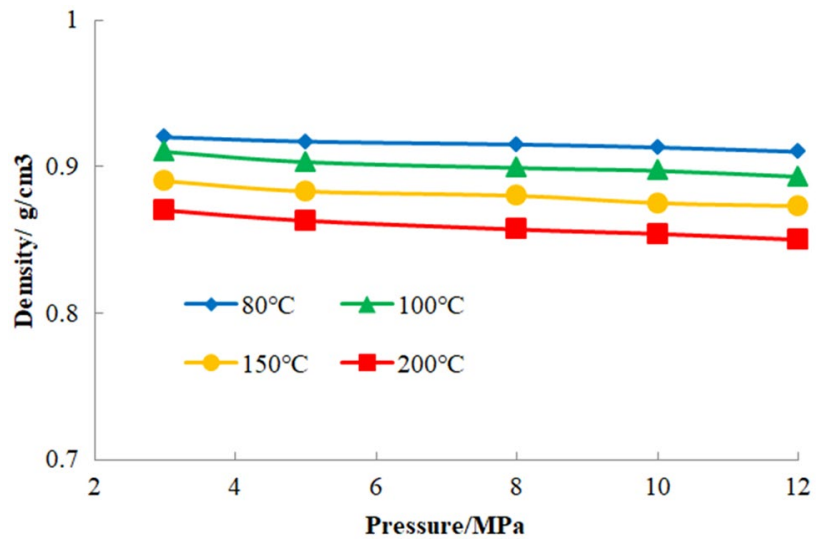

Fig. 8 Relationship between density of heavy oil saturated with $\mathrm{N}_{2}$ and pressure at different temperature

was $3 \mathrm{MPa}$ and temperature was $200{ }^{\circ} \mathrm{C}$, the solubility of $\mathrm{CO}_{2}$ and $\mathrm{N}_{2}$ in the heavy oil was 13.35 and $2.1 \mathrm{Sm}^{3} / \mathrm{m}^{3}$, respectively. In summary, although a high temperature had a negative effect on the solubility of $\mathrm{CO}_{2}$ in the heavy oil, $\mathrm{CO}_{2}$ still had a better solubility in heavy oil at $200{ }^{\circ} \mathrm{C}$.

\section{The effect of $\mathrm{CO}_{2}$ and $\mathrm{N}_{2}$ on the density of heavy oil}

Figures 7 and 8 show the relationship between density of heavy oil saturated with gas and pressure at different designated temperature. As the pressure and temperature increased, the density of heavy oil saturated with $\mathrm{CO}_{2}$ or $\mathrm{N}_{2}$ decreased. The reason might be when the temperature increased, the volume of heavy oil expanded and the space between molecular increased, so the density decreased. When the pressure increased, more $\mathrm{CO}_{2}$ or $\mathrm{N}_{2}$ dissolved into the heavy oil that increased the space between molecular; hence, the density of heavy oil would also decreased. When the temperature was $200^{\circ} \mathrm{C}$, the density of heavy oil 
saturated with $\mathrm{CO}_{2}$ decreased from 0.853 to $0.834 \mathrm{~g} / \mathrm{cm}^{3}$ as the pressure increased from 3 to $12 \mathrm{MPa}$, which of heavy oil saturated with $\mathrm{N}_{2}$ decreased from 0.872 to $0.856 \mathrm{~g} / \mathrm{cm}^{3}$ as the pressure increased from 3 to $12 \mathrm{MPa}$.

\section{The effect of $\mathrm{CO}_{2}$ and $\mathrm{N}_{2}$ on the viscosity of heavy oil}

Figures 9 and 10 show the relationship between viscosity of heavy oil saturated with gas and pressure at a given temperature. Compare the change of density and viscosity with pressure and temperature in Figs. 7, 8, 9, and 10. It was found that the density and viscosity had the same change trend with pressure and temperature. The viscosity of heavy oil saturated with $\mathrm{CO}_{2}$ or $\mathrm{N}_{2}$ decreased with the increase in pressure and temperature. It was because the change of pressure and temperature influenced the solubility of $\mathrm{CO}_{2}$ or $\mathrm{N}_{2}$ in heavy oil and the space between molecular. When the temperature was $200^{\circ} \mathrm{C}$, the viscosity of heavy oil saturated with $\mathrm{CO}_{2}$ decreased from 18.4 to $12.1 \mathrm{mPa} \cdot \mathrm{s}$ as the pressure increased from 3 to $12 \mathrm{MPa}$, which of heavy oil saturated with $\mathrm{N}_{2}$ decreased from 21.6 to $15.7 \mathrm{mPa} \cdot \mathrm{s}$ as the pressure increased from 3 to $12 \mathrm{MPa}$.

In summary, dissolution of $\mathrm{CO}_{2}$ or $\mathrm{N}_{2}$ in heavy oil will expand the volume of heavy oil and decrease the density and viscosity. The solubility of $\mathrm{CO}_{2}$ in heavy oil is bigger than that of $\mathrm{N}_{2}$, so $\mathrm{CO}_{2}$ is more easily dissolved in the heavy oil and mainly plays the role of reducing oil viscosity. Although the effect of $\mathrm{N}_{2}$ injection on reducing density and viscosity is not obvious, $\mathrm{N}_{2}$ has a large compression coefficient due to its lower critical temperature and minimal dependence on temperature. As shown in Fig. 11, the compression coefficient of $\mathrm{N}_{2}$ increases with the increase in pressure, which is much higher than that of $\mathrm{CO}_{2}$, because the critical temperature of $\mathrm{N}_{2}$ is low, and the compressibility coefficient of $\mathrm{N}_{2}$ is less affected by temperature ( $\mathrm{Li} 2017$ ). So $\mathrm{N}_{2}$ injection will help maintain formation pressure, improve the steam

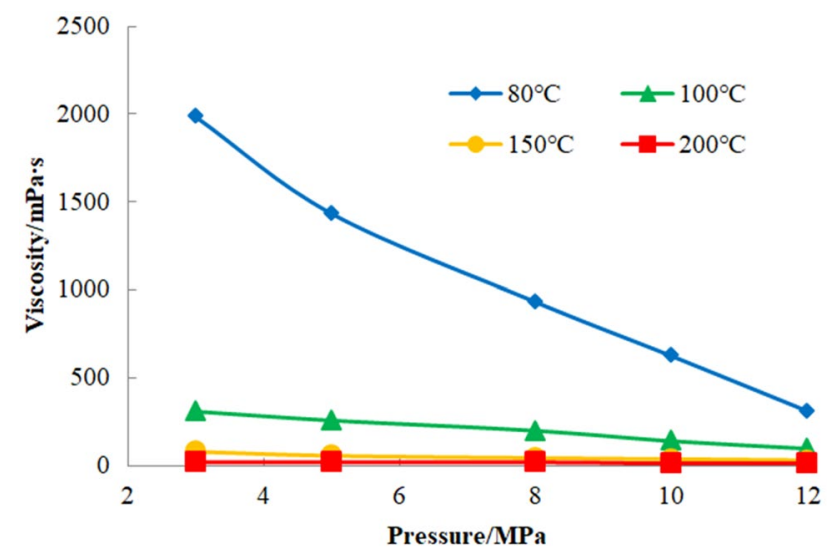

Fig. 9 Relationship between viscosity of heavy oil saturated with $\mathrm{CO}_{2}$ and pressure at different temperature



Fig. 10 Relationship between viscosity of heavy oil saturated with $\mathrm{N}_{2}$ and pressure at different temperature

sweep volume and increase the displacement efficiency, in addition, considering the lower thermal conductivity of $\mathrm{N}_{2}$, which is $0.0228 \mathrm{~W} /(\mathrm{m} \mathrm{K})$ At $0.1 \mathrm{MPa}$ and $0{ }^{\circ} \mathrm{C} . \mathrm{N}_{2}$ injection will promote steam migration, enhance the heat carrying capacity of steam and improve the heat utilization of steam.

\section{The results and discussion of huff and puff experiment}

\section{The development effect of different huff and puff experiments}

In order to compare the development effect of different huff and puff process and further reveal the development mechanism of multi-gas assisted steam huff and puff process, different huff and puff experiments were carried out at different designed temperature; namely, hot water huff and puff process, steam huff and puff process, multi-gas assisted steam huff and puff process were studied at $150{ }^{\circ} \mathrm{C}$ and 250 ${ }^{\circ} \mathrm{C}$, respectively.



Fig. 11 Comparison of compressibility coefficient for $\mathrm{N}_{2}$, air and $\mathrm{CO}_{2}$ at $200{ }^{\circ} \mathrm{C}$ 
Table 3 The change of four components after different huff and puff experiments

\begin{tabular}{llllll}
\hline Temperature $/{ }^{\circ} \mathrm{C}$ & Recovery methods & Asphaltene/\% & Resin/\% & Aromatics/\% & Saturates/\% \\
\hline Heavy oil & & 21.94 & 23.53 & 22.36 & 32.17 \\
150 & Hot water huff and puff & 22.61 & 22.67 & 22.41 & 32.31 \\
& Steam huff and puff & 22.89 & 18.2 & 22.89 & 36.02 \\
& Multi-gas assisted steam huff and puff & 23.05 & 17.65 & 23.03 & 22.54 \\
250 & Hot water huff and puff & 22.73 & 22.31 & 22.12 & 36.27 \\
& Steam huff and puff & 23.23 & 17.44 & 37.42 \\
& Multi-gas assisted steam huff and puff & 23.95 & 16.19 & 22.43 \\
\hline
\end{tabular}

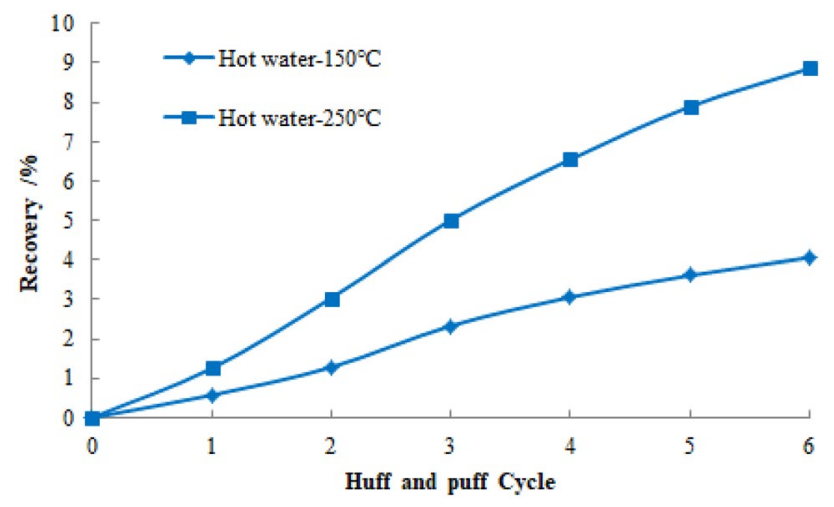

Fig. 12 The recovery of hot water huff and puff process at different temperature

Heavy oil is a complex and multi-component mixture that includes saturates, aromatics, resin and asphaltene (SARA, also called four components). Different development methods may destroy the component balance of heavy oil, which results in the change of four components content in the developed heavy oil (Kokal et al. 1992; Monin and Audibert 1987). In order to further study the development mechanism of different huff and puff process, as shown in Table 3, the SARA was analyzed after each huff and puff experiment. The results show that the content of saturates, aromatics and asphaltene increased, but the content of resin reduced from hot water huff and puff process to steam huff and puff process, and then to multi-gas assisted steam huff and puff process at each experiment temperature. Meanwhile, a higher content of asphaltene and lower content of resin appeared with the temperature increase.

Thermal expansion and viscosity reduction are still the main mechanism of thermal recovery. As shown in Fig. 1, the viscosity of heavy oil was very sensitive to the temperature. The viscosity of degassed heavy oil decreased exponentially as the temperature increased. But when the temperature was more than $150{ }^{\circ} \mathrm{C}$, the viscosity of heavy oil changed little with the increase in temperature.

Figure 12 shows the relation between huff and puff cycle and recovery of hot water huff and puff process. Figure 13

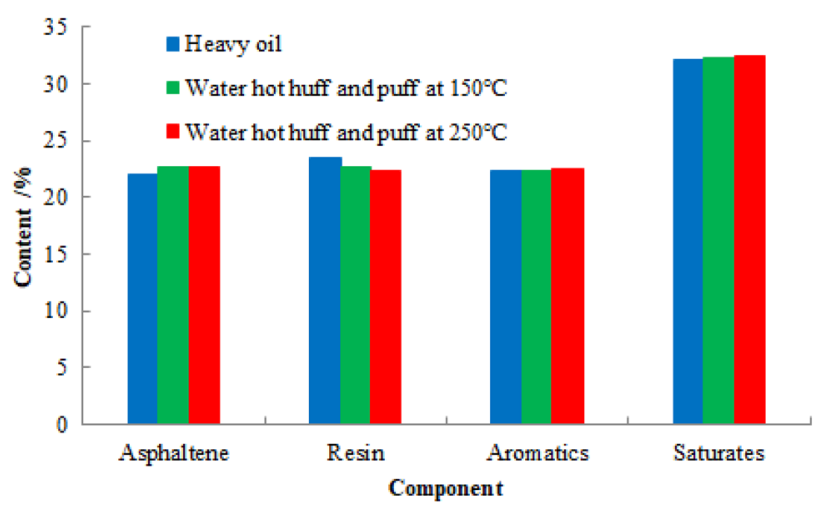

Fig. 13 The SARA change of hot water huff and puff process at different temperature

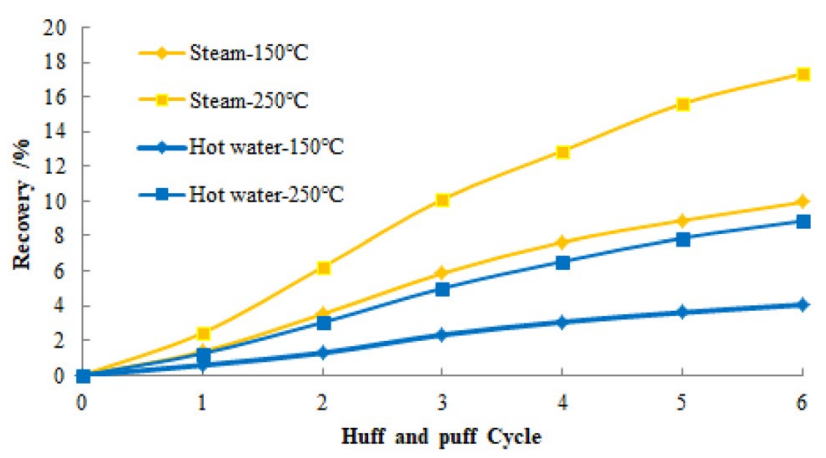

Fig. 14 The Recovery of hot water/steam huff and puff process at different temperature

shows the change of four components content after hot water huff and puff process at different temperature. As shown in Fig. 13, when the temperature rose from $150{ }^{\circ} \mathrm{C}$ to $250{ }^{\circ} \mathrm{C}$, the four components of heavy oil changed little after hot water huff and puff process. It indicated that heavy oil had not occurred obvious physicochemical reaction, so the main mechanism of hot water huff and puff process was viscosity reduction and thermal expansion.

Figure 14 compares the recovery between hot water huff and puff process and steam huff and puff process. As shown 


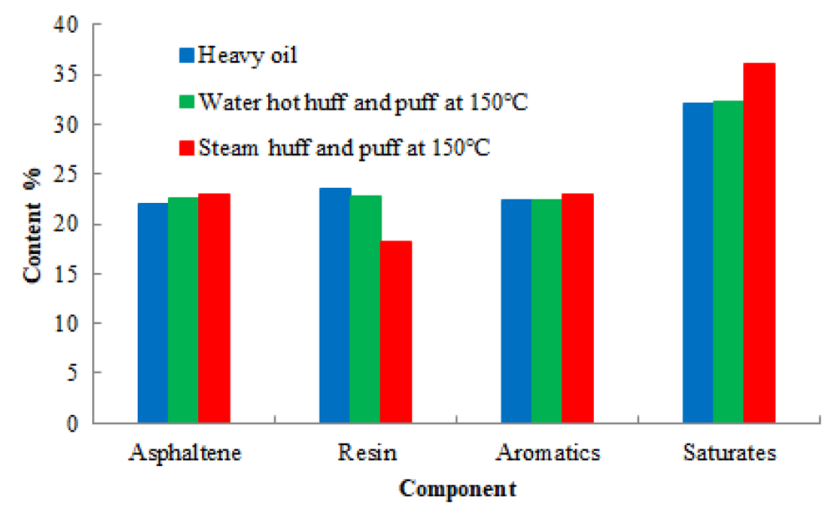

Fig. 15 The SARA change of hot water/steam huff and puff process at $150^{\circ} \mathrm{C}$

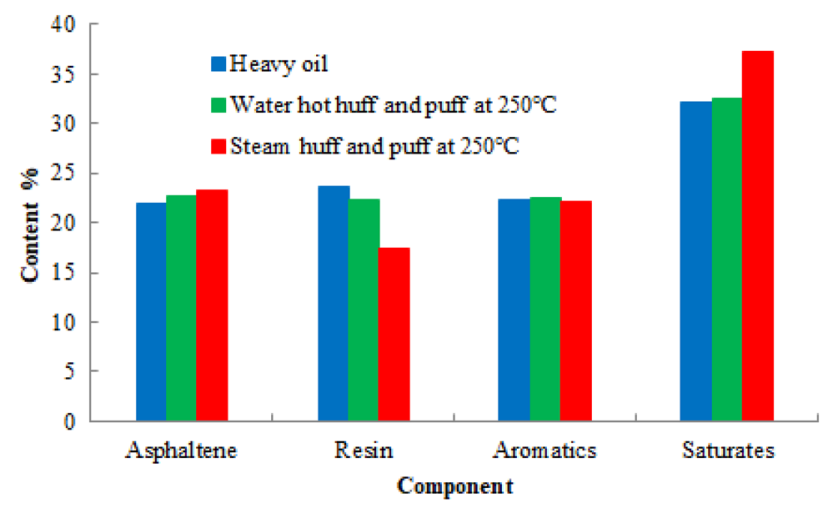

Fig. 16 The SARA change of hot water/steam huff and puff process at $250^{\circ} \mathrm{C}$

in Fig. 14, compared with hot water huff and puff process, the recovery of steam huff and puff process had obviously increased. Figures 15 and 16 show the change of four components content after hot water huff and puff process and steam huff and puff process at different temperature. In the course of steam huff and puff, when the temperature increased from 150 to $250{ }^{\circ} \mathrm{C}$, the content of saturates, aromatics and asphaltene increased, but the content of resin reduced. It indicates that the aquathermal cracking reaction had occurred in the steam huff and puff process. In the later period of experiment, the condensate of liquid hydrocarbon appeared in the beaker wall, which proved that steam distillation also had occurred. Therefore, in addition to viscosity reduction and thermal expansion, the recovery mechanism of steam huff and puff process also consisted of hydrothermal cracking reaction and steam distillation.

Figure 17 shows the recovery of three different huff and puff experiments. As shown in Fig. 17, the recovery of multi-gas assisted steam huff and puff process was further improved compared with hot water/steam huff and puff process due to the synergistic effect of multi-gas and steam. The

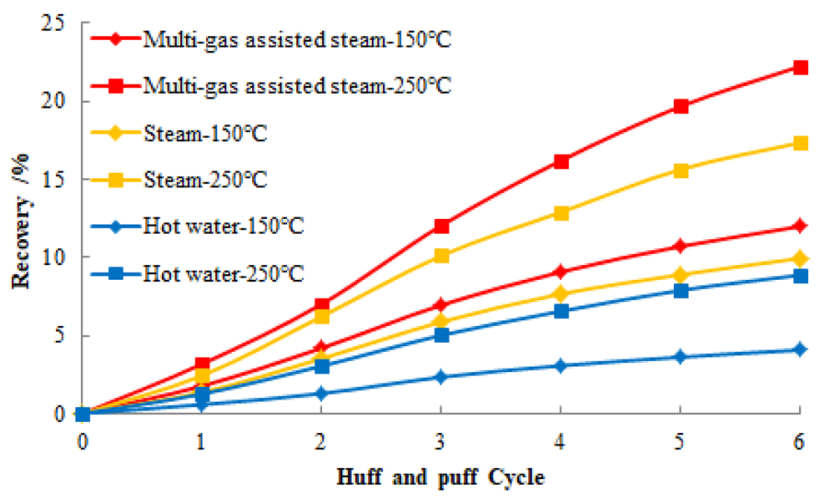

Fig. 17 The recovery of three different huff and puff process at different temperature

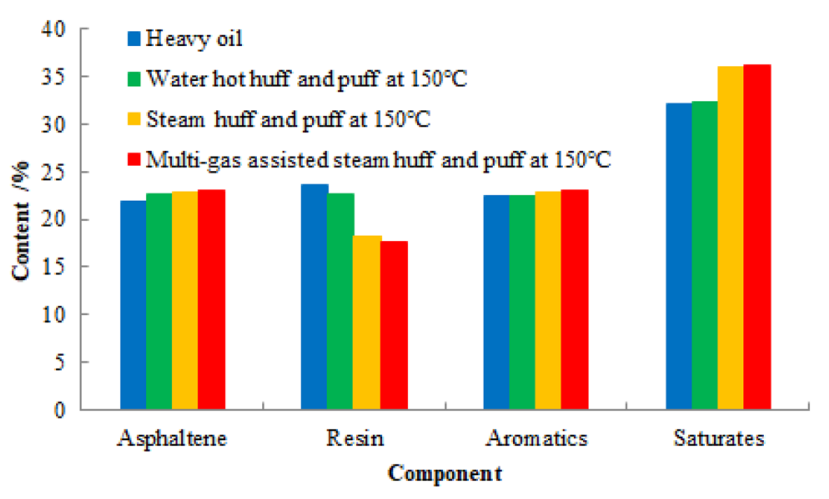

Fig. 18 The SARA change of three different huff and puff process experiment at $150^{\circ} \mathrm{C}$

recovery of multi-gas assisted steam huff and puff at $150{ }^{\circ} \mathrm{C}$ and $250{ }^{\circ} \mathrm{C}$ was $11.9 \%$ and $22.3 \%$, respectively, which was $7.9 \%$ and $2 \%$ higher than that of hot water huff and puff and steam huff and puff at $150{ }^{\circ} \mathrm{C}$, and $13.4 \%$ and $5 \%$ higher than that of hot water huff and puff and steam huff and puff at $250{ }^{\circ} \mathrm{C}$.

Figures 18 and 19 compare the change of four components content after three different huff and puff experiments at different temperature. As shown in Figs. 18 and 19, compared with hot water/steam huff and puff process, the four components content in the developed heavy oil of multigas assisted steam huff and puff process had exhibited more obvious change. What's more, at the same temperature, the content of asphaltene in the developed heavy oil of multigas assisted steam huff and puff process was the highest (Clark et al. 1984, 1987a, b; Clark and Hyne 1990). With the increase in temperature from 150 to $250{ }^{\circ} \mathrm{C}$, the content of saturates, aromatics and asphaltene obviously increased, but which of resin reduced. The result indicates that multi-gas injection in the process of steam huff and puff process had further broken the balance of heavy oil components and the 


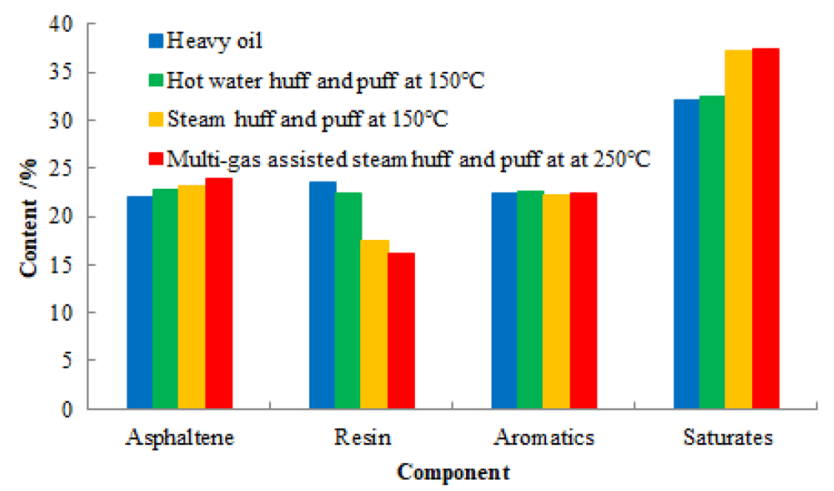

Fig. 19 The SARA change of three different huff and puff process experiment at $250^{\circ} \mathrm{C}$

aquathermal cracking reaction had played an important role during the multi-gas assisted steam huff and puff process. In addition, in the later period of multi-gas assisted steam huff and puff experiments, the condensate of liquid hydrocarbons also appeared in the beaker wall, and the amount was obviously more than that of steam huff and puff experiments. It indicates that injecting multi-gas had enhanced the steam distillation. What's more, from the HTHP PVT experiment, we have known that the $\mathrm{CO}_{2}$ and $\mathrm{N}_{2}$ could increase the expansion ratio, reduce the density and viscosity by dissolving in heavy oil, and $\mathrm{N}_{2}$ could maintain formation pressure, improve heating range and heat utilization of steam. All of the development mechanism further improved the recovery of multi-gas assisted steam huff and puff process.

\section{The optimization of key parameters for multi-gas assisted steam huff and puff process}

\section{1) Water-gas ratio}

Ensured that other parameters remain unchanged, which was to ensure the size of sand pack, initial pressure, initial porosity, initial saturation, steam injection temperature 250 ${ }^{\circ} \mathrm{C}$ and so on were the same. Six different water-gas volume ratio $(2: 8,3: 7,4: 6,5: 5,6: 4,7: 3)$ experiments of multi-gas assisted steam huff and puff process with 6 cycles were studied. The each cycle recovery and cumulative recovery of multi-gas assisted steam huff and puff process are shown in Figs. 20 and 21. It can be seen that with the increase in steam injection, cumulative recovery increased. When the water-gas ratio reached $4: 6$, the cumulative recovery began to decrease and the maximum cumulative recovery was acquired when the water-gas ratio was 4:6.

It could be known from the results of previous experimental studies that $\mathrm{CO}_{2}$ and $\mathrm{N}_{2}$ could dissolve into the heavy oil and reduce the viscosity and interfacial tension; furthermore, $\mathrm{N}_{2}$ had a low thermal conductivity that increased the sweep

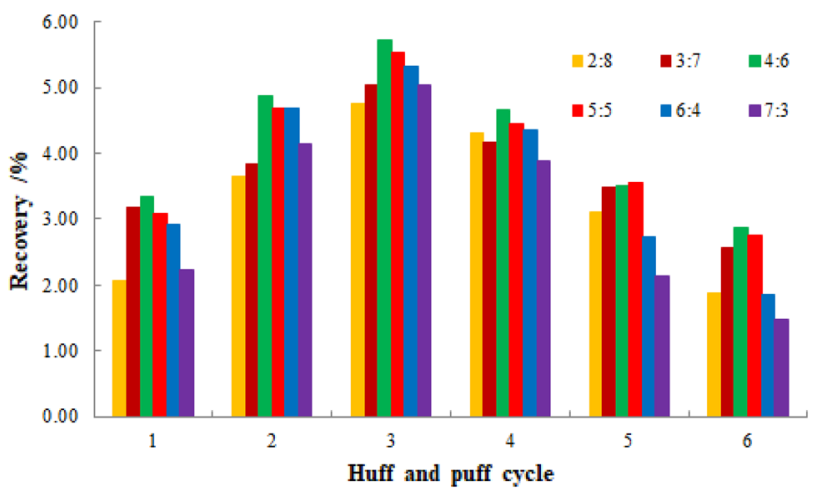

Fig. 20 Each cycle recovery of multi-gas assisted steam huff and puff process with different water-gas ratio

volume and heat utilization of steam. As a result, multigas assisted steam huff and puff process could more effectively improve the micro-displacement efficiency of steam and reduce residual oil saturation than steam huff and puff process. In the process of experiments, with the increase in steam ratio, the heat injection increased greatly, which increased the steam sweep volume and viscosity reduction area, thus effectively improved the development effect of thermal recovery. However, as the water-gas ratio increased, the Jia Min effect would be formed at the throat to prevent the flow of gas and increase the pressure in immediate vicinity of wellbore due to the heat loss and steam transforming to hot water, which made the injection difficult and a large amount of fluid cannot be effectively injected. At the same time, due to the decrease of the amount of injected gas, the dissolved gas of oil was reduced, which weakened the expansion energy and viscosity reduction of heavy oil, so the cumulative recovery would reduce. Therefore, the optimal water-gas ratio was 4:6.

\section{2) Steam injection temperature}

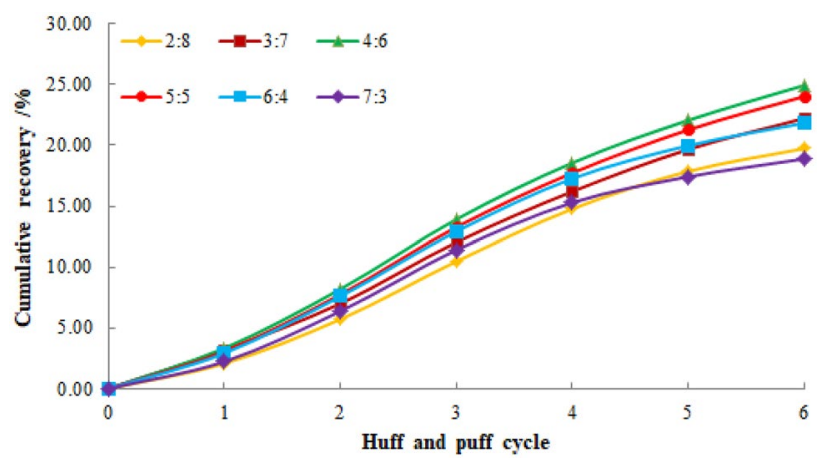

Fig. 21 The cumulative recovery of multi-gas assisted steam huff and puff process with different water-gas ratio 


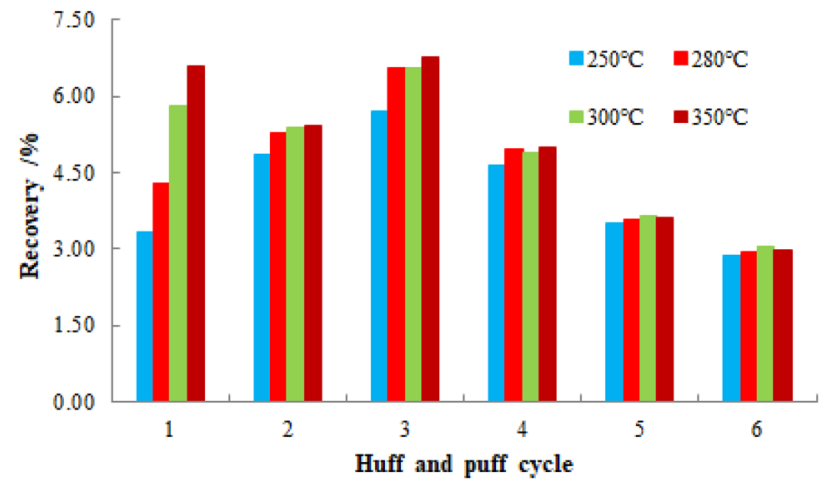

Fig. 22 Each cycle recovery of multi-gas assisted steam huff and puff process at different injection temperature

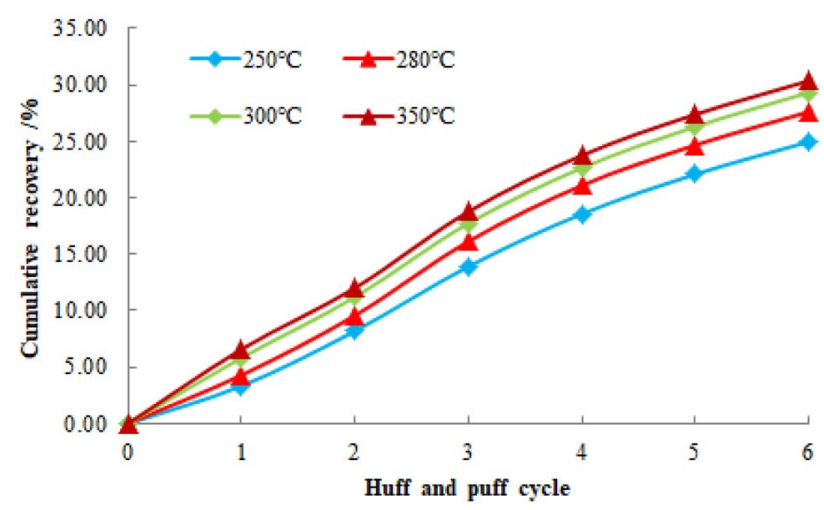

Fig. 23 The cumulative recovery of multi-gas assisted steam huff and puff process at different injection temperature

Ensured that other parameters remain unchanged, which was to ensure the size of sand pack, initial pressure, initial porosity, initial saturation, water-gas ratio $4: 6$ and so on were the same. Four different steam injection temperature $\left(250{ }^{\circ} \mathrm{C}, 280{ }^{\circ} \mathrm{C}, 300{ }^{\circ} \mathrm{C}, 350{ }^{\circ} \mathrm{C}\right)$ experiments of multi-gas assisted steam huff and puff process with 6 cycles were studied.

The each cycle recovery and cumulative recovery are shown in Figs. 22 and 23. As the steam injection temperature rose, the cumulative recovery increased. The cumulative recovery of 4 groups of experiments was $24.93 \%$, $27.61 \%, 29.32 \%$ and $30.35 \%$, respectively, the cumulative recovery was the highest at $350{ }^{\circ} \mathrm{C}$, but the cumulative recovery was little different between 300 and $350{ }^{\circ} \mathrm{C}$. The reason could be that as the steam injection temperature increased, both viscosity reduction degree of heavy oil and oil flow capacity in the formation increased; in addition, the thermal expansion of heavy oil increased the oil saturation in the formation. However, constantly increasing steam injection temperature would reduce the dissolved gas and weaken the amplitude of volume expansion and viscosity reduction of heavy oil. Therefore, after reaching a certain steam injection temperature, although steam injection temperature still increased, volume expansion and viscosity reduction of heavy oil were not obvious. And the excessive temperature easily caused the heavy components of heavy oil to coke, which leaded to the blockage of the pore, and reduced the permeability and cumulative recovery. So the optimal steam injection temperature was $300{ }^{\circ} \mathrm{C}$.

\section{Conclusions}

1. After injecting $\mathrm{CO}_{2}$ or $\mathrm{N}_{2}$, the solubility of gas in degassed heavy oil increased as the pressure increased. With the increase in temperature, the solubility of $\mathrm{CO}_{2}$ decreased and the solubility of $\mathrm{N}_{2}$ increased. Under the same condition, the solubility of $\mathrm{CO}_{2}$ was obvious higher than that of $\mathrm{N}_{2}$. Due to the dissolving of $\mathrm{N}_{2}$ and $\mathrm{CO}_{2}$, the density and viscosity of heavy oil decreased as the pressure increased.

2. Injecting multi-gas and steam could break the balance of heavy oil component. With the increase in temperature, the content of resin reduced and the content of saturates, aromatics and asphaltene increased. Except for thermal expansion and viscosity reduction, the hydrothermal cracking reaction and steam distillation were also the important mechanism of enhanced oil recovery for multi-gas assisted steam huff and puff process.

3. Multi-gas assisted steam huff and puff process increased the recovery by $2-5 \%$ compared with steam huff and puff process. The optimal water-gas ratio and steam injection temperature which were $4: 6$ and $300{ }^{\circ} \mathrm{C}$, respectively, were optimized by experiment. Considering that multigas assisted steam huff and puff process had higher recovery, it is suggested to further study the optimal value of injection-production parameters to excavate the greatest potential of multi-gas assisted steam huff and puff process for developing the offshore heavy oil reservoirs.

Acknowledgements We acknowledge the State Key Laboratory Projects of China (KL17032) to provide research funding. The authors also wish to thank the State Key Laboratory of efficient development of offshore oil, Beijing, Bohai oilfield for the financial and crude oils support for this research.

Funding This study was funded by the Department of well completion at the SINOPEC Research Institute of Petroleum Engineering. 


\section{Declarations}

Conflict of interest On behalf of all the co-authors, the corresponding author states that there is no conflict of interest.

Open Access This article is licensed under a Creative Commons Attribution 4.0 International License, which permits use, sharing, adaptation, distribution and reproduction in any medium or format, as long as you give appropriate credit to the original author(s) and the source, provide a link to the Creative Commons licence, and indicate if changes were made. The images or other third party material in this article are included in the article's Creative Commons licence, unless indicated otherwise in a credit line to the material. If material is not included in the article's Creative Commons licence and your intended use is not permitted by statutory regulation or exceeds the permitted use, you will need to obtain permission directly from the copyright holder. To view a copy of this licence, visit http://creativecommons.org/licenses/by/4.0/.

\section{References}

Bao Y, Wang J, Gates ID (2016) On the physics of cyclic steam stimulation. Energy 115(1):969-985

Butler RM, Jiang Q, Yee CT (2000) Steam and gas push (SAGD)-4; recent theoretical developments and laboratory results using layered models. J Can Pet Technol 40(1):54-61

Clark PD, Hyne JB, Tyrer JD (1984) Chemistry of organosulfur compound type occurring in heavy oil sands: 3. Reaction of Thiophene and Tetrahydrothiophene with Vanadyl and Nickel Salts. Fuel 63(6):1645-1649

Clark PD, Dowling NI, Lesage KL, Hyne JB (1987a) Chemistry of organosulphur compound types occurring in heavy oil sands: 5. Reaction of thiophene and tetrahydrothiophene with aqueous group metal species at high temperature. Fuel 66(12):1699-1702

Clark PD, Hyne JB, Tyrer JD (1987b) Chemistry of organosulfur compound type occurring in heavy oil sands: 4 . The high temperature reaction of thiophene and tetrahydrothiphene with aqueous solution of aluminum and first row transition-metal cations. Fuel 66:1353-1357

Clark PD, Hyne JB (1990) Studies on the chemical reactions of heavy oils under steam stimulation condition. AOSTRA. J. Res 6(1):29-39

Dong M, Huang S (2002) Flue gas injection for heavy oil recovery. J Can Pet Technol 41(09):44-50

Dong X, Liu H, Zhang Z, Wang C (2014) The flow and heat transfer characteristics of multi-thermal fluid in horizontal wellbore coupled with flow in heavy oil reservoirs. J Pet Sci Eng 122:56-68

Dong X, Liu H, Zhang Z, Wang L, Chen Z (2016) Performance of multiple thermal fluids assisted gravity drainage process in post SAGD reservoirs. J Pet Sci Eng 154:528-536

Fan J, Li XF, Qin TJ (2016) Feasibility study on steam and gas push with dual horizontal wells in a moderate-depth heavy oil reservoir. J Eng Sci Technol Rev 9(1):151-158

Fan JJ, Jin B, YangFan JX (2019) The flue gas-solvent assisted steam assisted gravity drainage studies: experiments and numerical simulation in extra-heavy oil reservoirs. Energy Sour Part A Recov Util Environ Eff 9:1-17

Firouz AQ, Torabi F (2014) Utilization of carbon dioxide and methane in huff-and-puff injection scheme to improve heavy oil recovery. Fuel 117(1):966-973
Gao Y, Liu S, Shen D (2003) Study on n2 and solvent assisted steam stimulation in a super-heavy oil reservoir. Pet Explor Dev 30(2):73-75

Gu GM, Lin T, Sun YT (2007) Multi-component thermal fluid technology on extra-heavy oil to enhance oil recovery in Bohai Bay of China. In: The twenty fourth international ocean and polar engineering conference, Busan, Korea

Hatzikiriakos SG (2014) Rheology of bitumen: effects of temperature, pressure, $\mathrm{CO}_{2}$ concentration and shear rate. Fuel 116(1):578-587

Hong KC, Ault JW (1984) Effects of noncondensable gas injection on oil recovery by steam flooding. J Pet Technol 36(12):2160-2170

Jha KN (1986) A laboratory study of heavy oil recovery with carbon dioxide. J Can Pet Technol 25(2):54-63

Jin F, Dong L, Pu W, Li Y, Wang N (2017) Utilisation of multiple gas injection to enhance oil recovery for fractured-cavity carbonate heavy oil reservoir. Int J Oil Gas Coal Technol 15(1):77-93

Kavousi A, Torabi F, Chan CW, Shirif E (2014) Experimental measurement and parametric study of $\mathrm{Co}_{2}$ solubility and molecular diffusivity in heavy crude oil systems. Fluid Phase Equilib 371(12):57-66

Kokal SL, Najman J, Sayegh SG (1992) Measurement and correlation of asphaltene precipitation from heavy oils by gas injection. J Can Pet Technol 31(4):24-30

Li B, Zhang Q, Li S, Li Z (2017) Enhanced heavy oil recovery via surfactant-assisted $\mathrm{Co}_{2}$ huff-n-puff processes. J Pet Sci Eng 159:25-34

Li, G.M (2017) Experimental research on gas mixing flooding technology to improve steam flooding effect. $21-23$

Liu HQ (2013) Thermal recovery principle and method. Petroleum Industry Press, Beijing

Liu P, Zhang X, Hao M, Liu J, Yuan Z (2016) Parameter optimization of gas alternative water for $\mathrm{CO}_{2}$ flooding in low permeability hydrocarbon reservoirs. J Renew Sustain Energy 8(3):035901

Liu XH, Zhang FY, Huang K (2011) Discussion about the thermal recovery of nb35-2 offshore heavy oilfield. Reserv Eval Dev $1(2): 61-63$

Mohsenzadeh A, Escrochi M, Afraz MV, Karimi G, Al-Wahaibi Y, Ayatollahi S (2016) Non-hydrocarbon gas injection followed by steam-gas co-injection for heavy oil recovery enhancement from fractured carbonate reservoirs. J Pet Sci Eng 144:121-130

Monin JC, Audibert A (1987) Thermal cracking of heavy oil/mineral matrix systems. In: SPE international symposium on oilfield chemistry

Song C, Yang D (2017) Experimental and numerical evaluation of $\mathrm{CO}_{2}$ huff-n-puff processes in bakken formation. Fuel 190:145-162

Srivastava RK, Huang SS, Mourits FM (1997) A laboratory evaluation of suitable operating strategies for enhanced heavy oil recovery by gas injection. J Can Pet Technol 36(2):33-41

Sun F, Yao Y, Li X, Yu P, Lin Z, Yi Z (2017) A numerical approach for obtaining type curves of superheated multi-component thermal fluid flow in concentric dual-tubing wells. Int J Heat Mass Transf 111:41-53

Sun F, Yao Y, Li X, Li G, Liu Q, Han S et al (2018a) Effect of friction work on key parameters of steam at different state in toepoint injection horizontal wellbores. J Pet Sci Eng 164:1-27

Sun F, Yao Y, Li X (2018b) The heat and mass transfer characteristics of superheated steam coupled with non-condensing gases in horizontal wells with multi-point injection technique. Energy 143:995-1005

Sun F, Yao Y, Li G (2019) Comments on heat and mass transfer characteristics of steam in a horizontal wellbore with multipoint injection technique considering wellbore stock liquid. Int J Heat Mass Transf 132:1319-1321 
Telmadarreir A, Doda A, Trivedi JJ, Kuru E, Choi P (2016) $\mathrm{CO}_{2}$ microbubbles-a potential fluid for enhanced oil recovery: bulk and porous media studies. J Pet Sci Eng 138:160-173

Wang K, Wei Y, Deng J, Ye Hao T, Ye s (2018) Experimental study on $\mathrm{h}_{2} \mathrm{~S}$ and $\mathrm{Co}_{2}$ generation capacities of the Bohai bay heavy oil. J Pet Sci Eng 167:241-248

Wang WH, Wang JR, Dang LI, Dong ZY, Gao XT, Ai JX et al (2004) Optimization of steam stimulation injection-production parameter system in heavy oil. Pet Explor Dev. 2:37-44

Wang Y, Ren S, Zhang L, Peng X, Pei S, Cui G et al (2017) Numerical study of air assisted cyclic steam stimulation process for heavy oil reservoirs: recovery performance and energy efficiency analysis. Fuel 211:471-483

Wu Z, Liu H, Zhang Z, Wang X (2018) A novel model and sensitive analysis for productivity estimate of nitrogen assisted cyclic steam stimulation in a vertical well. Int J Heat Mass Transf 126:391-400

Yan H, Liu Z, Zhang J, Xiao F, Fan T (2020) Study of associated gas components and combustion characteristics based on nitrogenassisted steam stimulation of heavy oils. Fuel 282(1):118819

Yoelin (1970) Tm-sand steam stimulation project, Huntington beach offshore field - a remarkable example of a heavy oil reservoir responding to the cyclic steam injection process. Soc.pet.eng. aime Pap. Soc. Pet. Eng. AIME, Pap.; (United States), spe-3104

Publisher's Note Springer Nature remains neutral with regard to jurisdictional claims in published maps and institutional affiliations. 